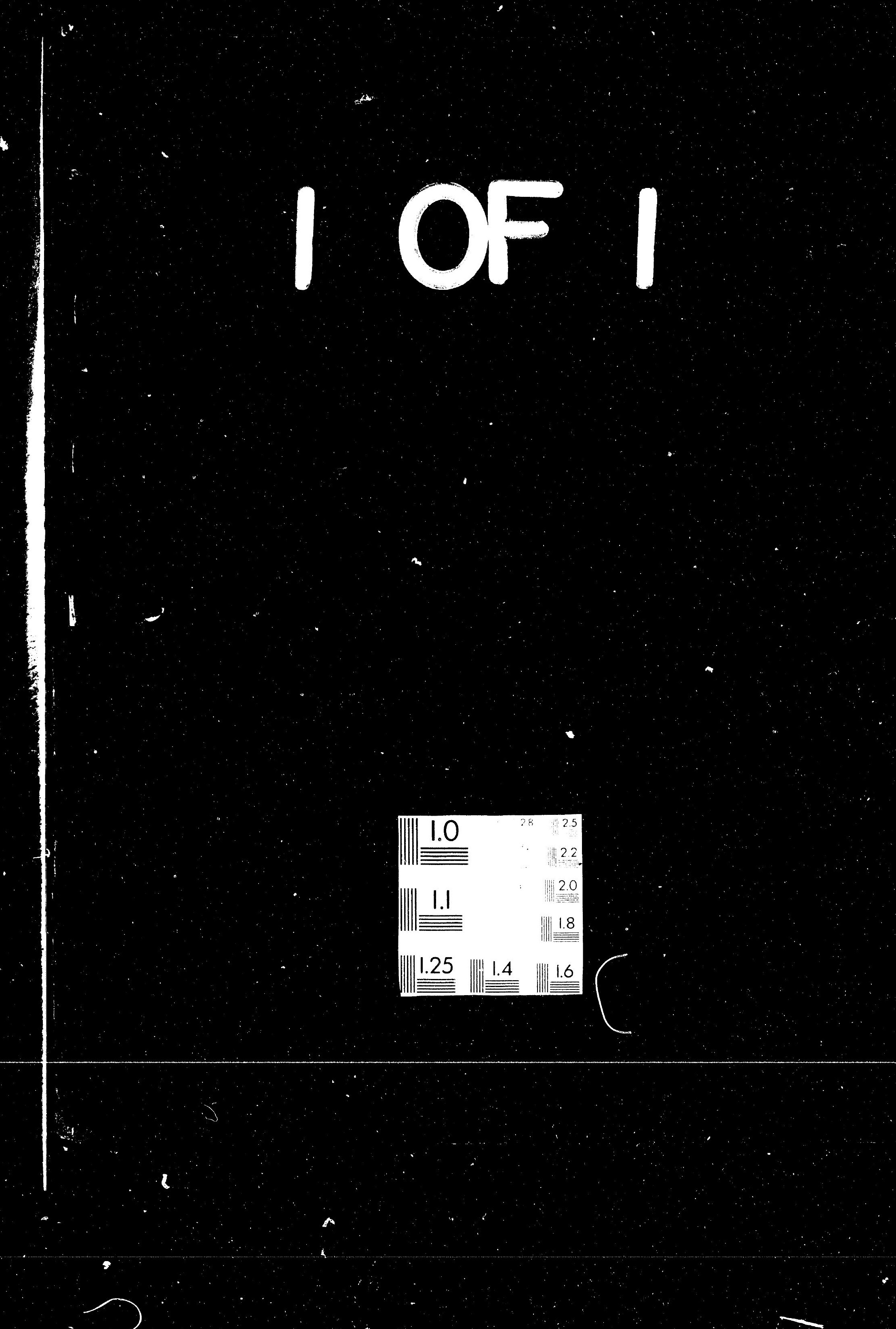




\title{
TESTING OF A CRYOGENIC RECOOLER HEAT EXCHANGER AT BROOKHAVEN NATIONAL LABORATORY*
}

\author{
Anthony Nicoletti, K.C. Wu \\ Brookhaven National Laboratory \\ RHIC Collider Ring Division \\ Upton, NY 11973-5000
}

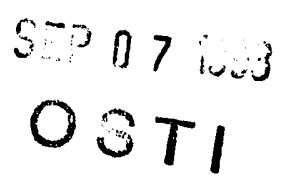

\begin{abstract}
Brookhaven National Laboratory has tested a recooler heat exchanger intended to be used in the cryogenic system of the Relativistic Heavy Ion Collider. The unit is required to transfer 225 Watts from a supercritical helium stream flowing at $100 \mathrm{~g} / \mathrm{s}$ to a helium bath boiling at $4.25 \mathrm{~K}$. Measurements made with heat loads of 50 to over 450 Watts on the unit indicate its cooling capacity is greater than $400 \mathrm{Watts}$, as expected, and it will be suitable for use in the RHIC ring. Presented are the modifications made to BNL's MAGCOOL test facility that were necessary for testing, test procedure, and recooler performance.
\end{abstract}

\section{INTRODUCTION}

\section{RHIC Helium Distribution System}

A cold circulating compressor at the six o'clock crossing region of each ring of the Relativistic Heavy Ion Collider will enable magnet pressure and flow to be controlled independent of the main refrigerator. This allows the magnet coolant loop pressure to rise without venting ( within predetermined limits ) of cold helium during temperature excursions, such as a magnet quench. Containing the cold helium in the magnets also minimizes the refrigeration required to recover from such an upset. With this scheme, however, heat must be removed from the magnet coolant stream in order to maintain the collider at its operating temperature. Therefore, a series of heat exchangers spaced throughout each ring will be used to periodically recool the circulating helium to its design point temperature. Each ring will have thirty recoolers designed to extract 50 Watts from the magnet coolant stream and 6 units sized for $225 \mathrm{~W}$ atts of heat transfer. The recoolers will be pool boiling type, with the bath fed by a supply header and the saturated gas

\footnotetext{
Work performed under contract with the U.S. Department of Energy
} 


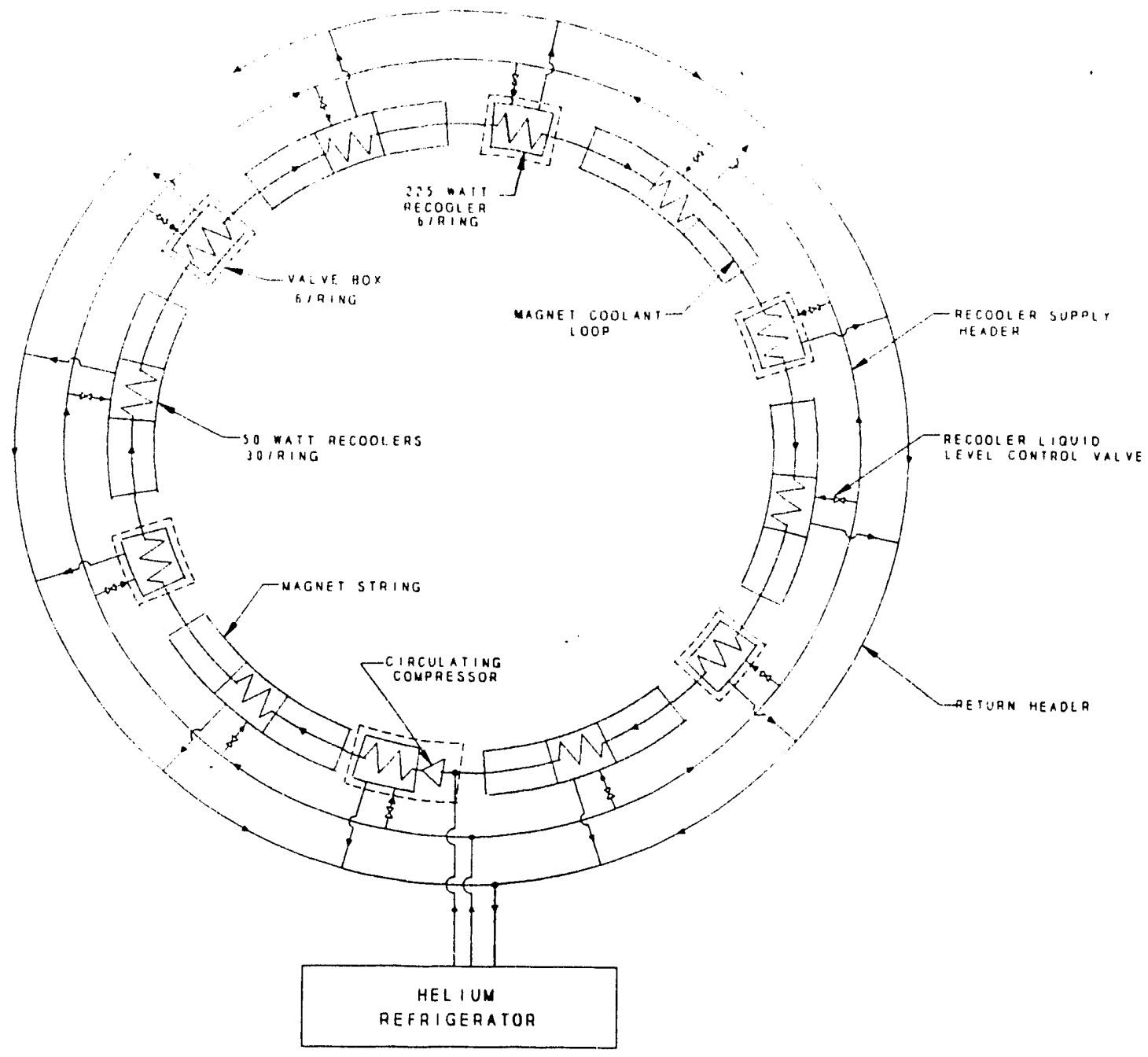

Figure 1: RHIC helium distribution system during steady state operation

returned to the refrigerator by a return header. The general flow circuit for one RHIC ring during steady state operation is shown in figure 1 .

The process schematic and expected normal operating parameters for the $225 \mathrm{Watt}$ recooler are shown in figure 2 . The $100 \mathrm{~g} / \mathrm{s}$ magnet coolant stream is cooled from $4.5 \mathrm{~K}$ to $4.3 \mathrm{~K}$ by flowing through a tube bundle immersed in a helium bath boiling at $4.25 \mathrm{~K}$. A superconducting level probe maintains liquid level in the bath by regulating $\mathrm{J} T$ flow from a supply header operating at approximately five atm. and $4.5 \mathrm{k}$ and the cold gas is returned to the refrigerator by a cold return header operating at $4.3 \mathrm{k}$ and slightly above atmospheric pressure. The unit and all local associated piping will be internal to a valve box located at each of the 6 crossing regions of the RHIC ring. Over the past year and a half, a prototype $225 \mathrm{Watt}$ recooler heat exchanger was designed and built by Janis Inc. and tested by BNL at its MAGCOOL magnet test facility.

\section{RECOOLER DESCRIPTION}

The dual pass pin fin heat exchanger contains a bundle of 12 parallel $3 / 4$ inch od 


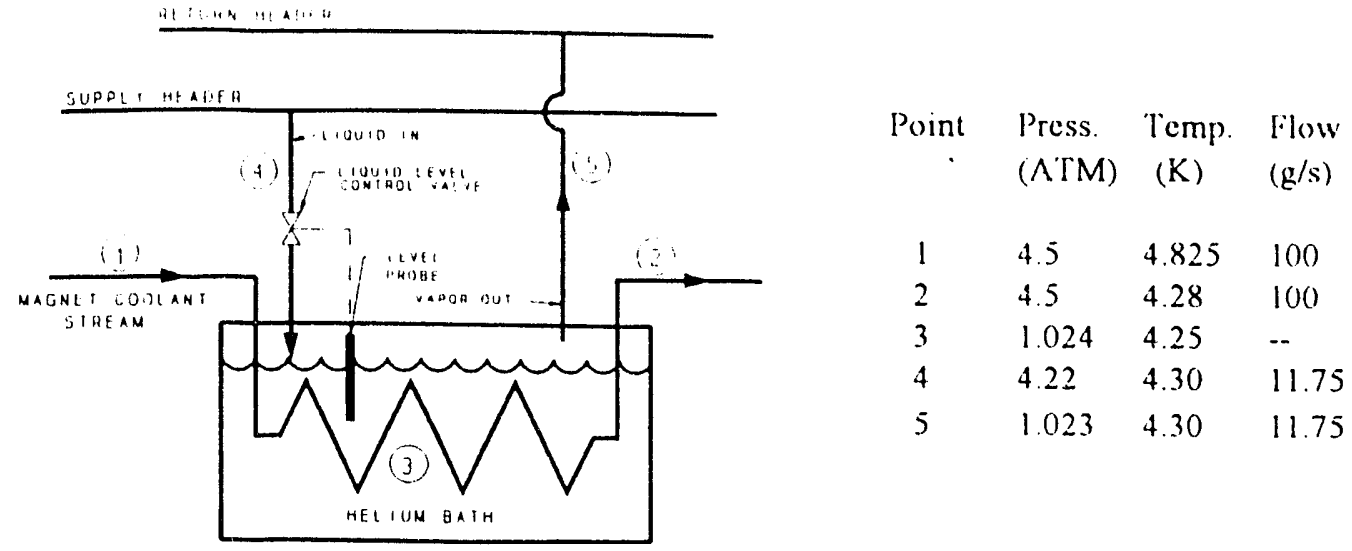

Figure 2: Recooler flow schematic and design process points

copper tubes of .065 wall thickness in a shell of approximately 450 liters. The tubes and the pin fin loop spiral soldered to them provide an effective heat transfer surface of 721.5 $\mathrm{cm}^{2} / \mathrm{ft}$. The prototype is complete with its own vacuum vessel and $55 \mathrm{~K}$ heat shield with bayonet penetrations for all process piping. Built in is a $1 / 2$ inch valve which J-T's liquid into the shell side of the unit and which is controlied by a superconducting level probe.

\section{TEST SETUP}

BNL's MAGCOOL magnet test facility is normally used in the SSC and RHIC single magnet test programs. Its primary cold box, located at the cold end of the $1500 \mathrm{Watt}$ HEUB refrigerator, contains precooler and subcooler pool boiling heat exchangers, which normally operate at approximately $4.45 \mathrm{~K}$ and $4.3 \mathrm{~K}$ respectively. Mounted on the cold box is a cold compressor which circulates supercritical helium in a closed loop through the precooler and subcooler pots, and through supply and return headers which serve 5 bays available for magnet testing. The facility is monitored by a CRISP process control computer containing a real time data acquisition system and continuously updated computer console display of operating conditions. The unit was installed in the circulating loop in bay E. The helium bath was supplied from the magnet coolant line as it exited the recooler vacuum vessel and the shield was cooled by an independent nitrogen circuit. The flow schematic for the test and measure operation of the MAGCOOL cold box, with the recooler installed in the circulating loop, is shown in figure 3.

In normal SSC and RHIC magnet testing, there is no return flow of cold saturated helium gas, and consequently, there were no provisions for receiving this type of flow from a magnet in one of the bays. A transfer line was installed which connected the shell side of the heat exchanger being tested to the line inside the MAGCOOL cold box which carries saturated helium boiloff from the precooler heat exchanger back to the refrigerator. This modification not only allowed completion of recooler testing but also enables this facility to perform upcoming RHIC magnet string tests with smaller $50 \mathrm{~W}$ att recoolers installed inside magnet cryostats.

A pair of silicon diode sensors monitored temperature at the magnet coolant inlet and outlet, the helium bath, the J-T bath supply, and saturated vapor return. Pressure was recorded at the helium inlet and the cold gas return. Helium stream mass flow rate was measured by a venturi located in the cold box and helium boiloff rate was measured by a venturi in the newly installed vapor return transfer line. Heat load on the unit was the sum of background heat leak, which averaged $50 \mathrm{~W}$ atts and heat input from a calorimeter located in the MAGCOOL cold box, which was adjusted from 0 to 400 Watts. Data was 


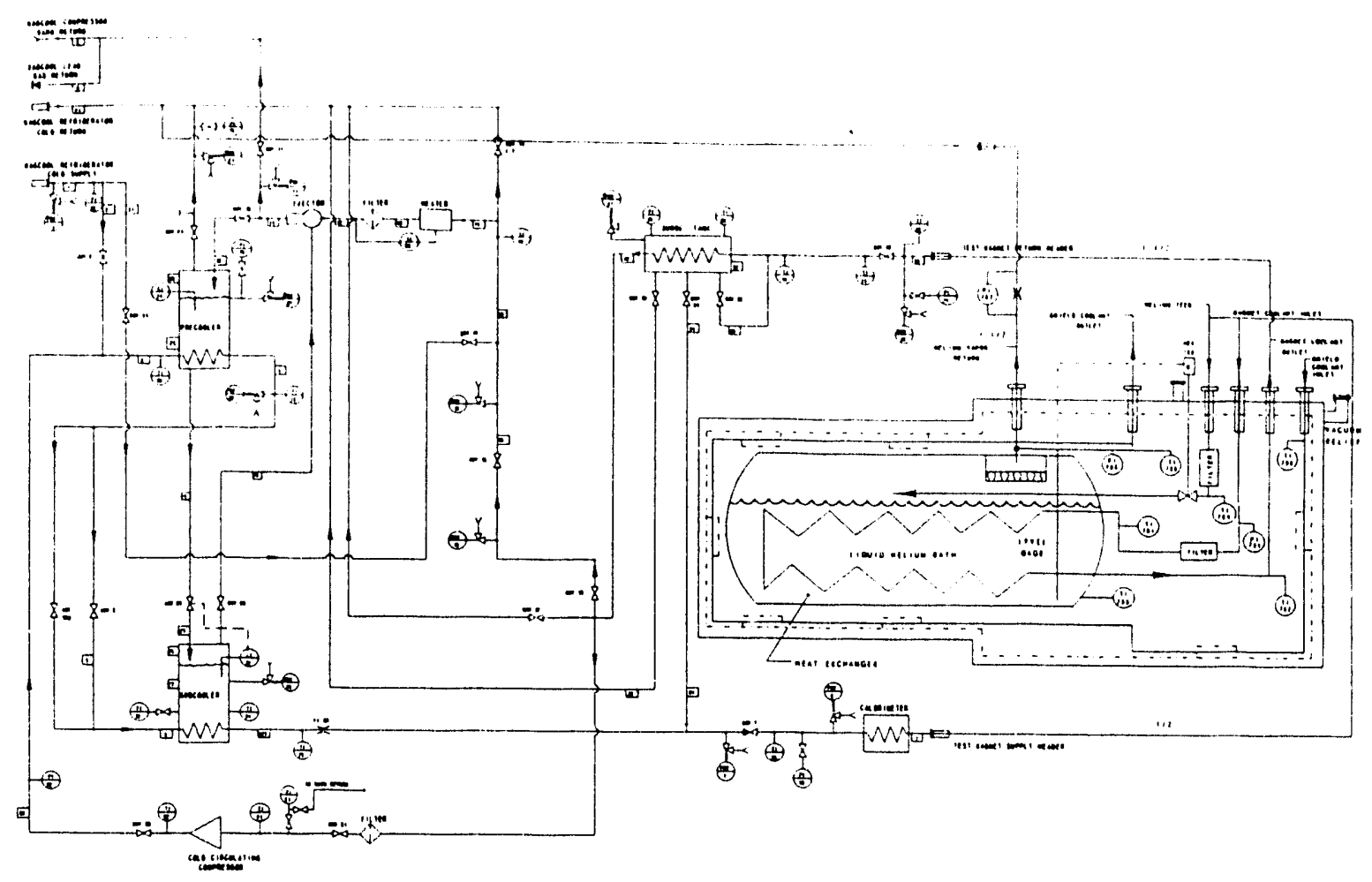

Figure 3: Flow schematic of the MAGCOOL test facility with the recooler installed in the circulating loop

taken at five minute intervals using the CRISP process controller. The system flow diagram and process controller as displayed on the computer are shown in figure 4.

\section{RESULTS}

\section{Condenser Mode}

Testing was done on three separate occasions with consistent offsets observed between redundant sensors at several process points, notably the critical helium stream outlet and recooler bath locations. In an attempt to investigate these readings over a range of temperatures, the helium pressure in the MAGCOOL subcooler heat exchanger was lowered until the helium entering stream entering on the tube side of the recooler was colder than the helium in its bath. The recorsler was acting as a condenser with heat being removed from the bath and added to the stream. As much as 80 watts of heat transfer was achieved, with this operating mode limited by the capacity of the refrigerator to subcool the helium in the subcooler pot. The errors in the readings were determined to be consistent over a wide temperatures range and subsequent testing determined the exact offsets, which are applied to the temperatures in this data analysis.

\section{Recooler Performance}

Figure 5 shows the temperatures at the helium stream inlet and outlet and the recooler bath as a function of total heat load at conditions as close to expected design conditions as MAGCOOL could provide.. Uncertainties in temperature readings make the coolant stream exit temperature indistinguishable from the recooler bath temperature over the entire range, 


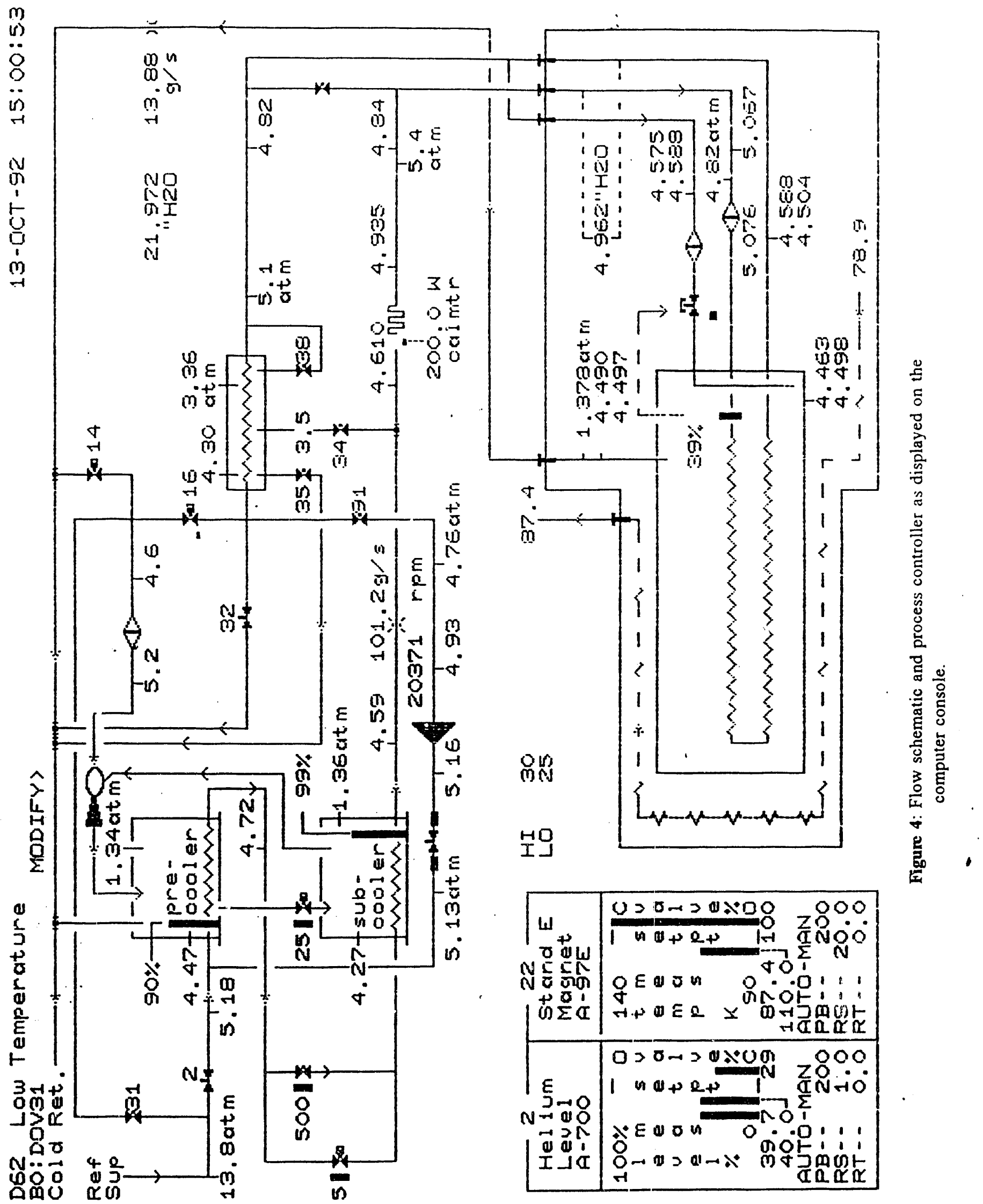


however, if worst case uncertainties are applied, the temperature of the helium exiting the recooler is sonsistently within $50 \mathrm{mK}$ of the temperature of the bath. The increase in pressure in the shell side of the recooler at higher heat loads is reflected in an increase in both the helium bath temperature and helium stream outlet temperature.

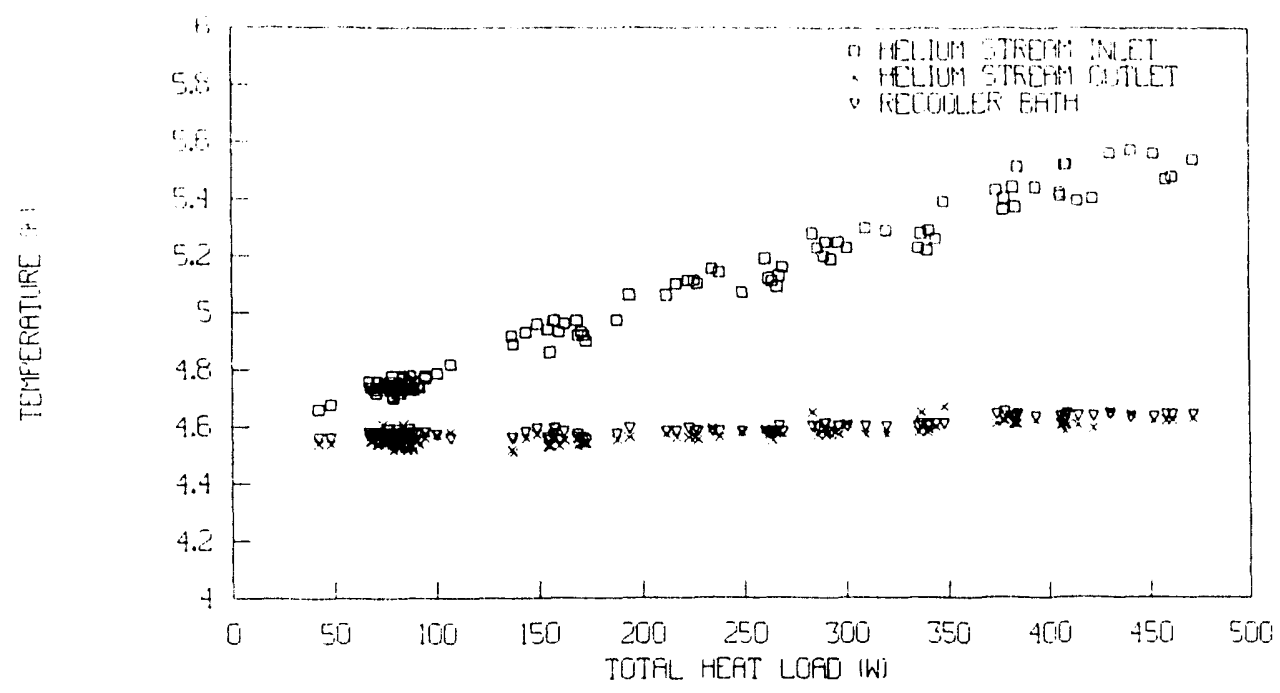

Figure 5: Variation of helium stream inlet and outlet and helium bath temperature with total recooler heat load.

Figure 6 shows the heat transferred as versus the recooler heat load with the unit operating near design conditions. The unit has a large excess capacity, as expected, in that only above 400 Watts is there a noticeable reduction in the percent of total heat removed by the recooler. This performance is expected since in its specifications, BNL requested factor of safety of 1.5 on the minimum required tube length.

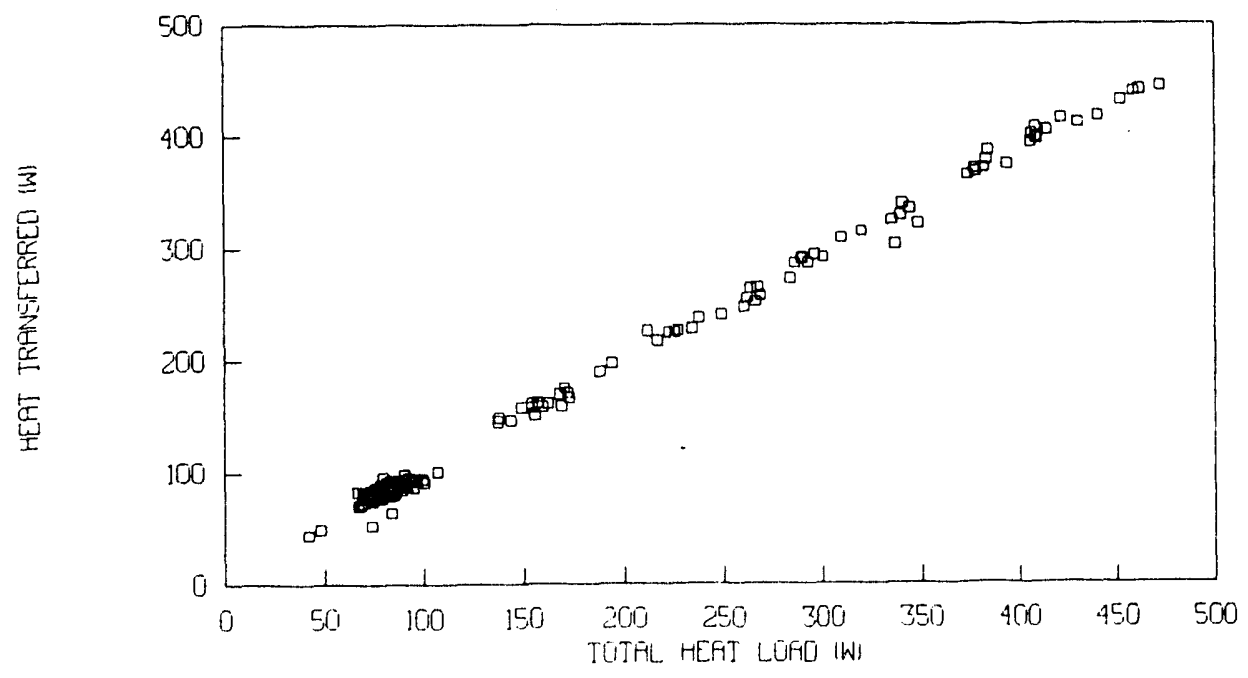

Figure 6: Heat transferred vs total heat load 


\section{CONCLUSIONS AND PLANS}

The prototype $225 \mathrm{~W}$ att recooler tested behaved as expected and has demonstrated ample capacity for meeting RHIC design requirements. The design will eventually' be used in the valve boxes throughout the RHIC ring. Its performance will be monitored during the first sextant test, which is scheduled for mid 1996, where it will be used in cooling the first set of magnets installed in the tunnel.

\section{ACKNOWLEDGEMENTS}

The authors wish to thank the MAGCOOL cryogenic operations group headed by R. Picinich, the instrumentation control group headed by W. Kollmer. and D. Zantopp for help with gathering data.

\section{DISCLAIMER}

This report was prepared as an account of work sponsored by an agency of the United States Government. Neither the United States Government nor any agency thereof, nor any of their employees, makes any warranty, express or implied, or assumes any legal liability or responsibility for the accuracy, completeness, or usefulness of any information, apparatus, product, or process disclosed, or represents that its use would not infringe privately owned rights. Reference herein to any specific commercial product, process, or service by trade name, trademark, manufacturer, or otherwise does not necessarily constitute or imply its endorsement, recommendation, or favoring by the United States Government or any agency thereof. The views and opinions of authors expressed herein do not necessarily state or reflect those of the United States Government or any agency thereof. 

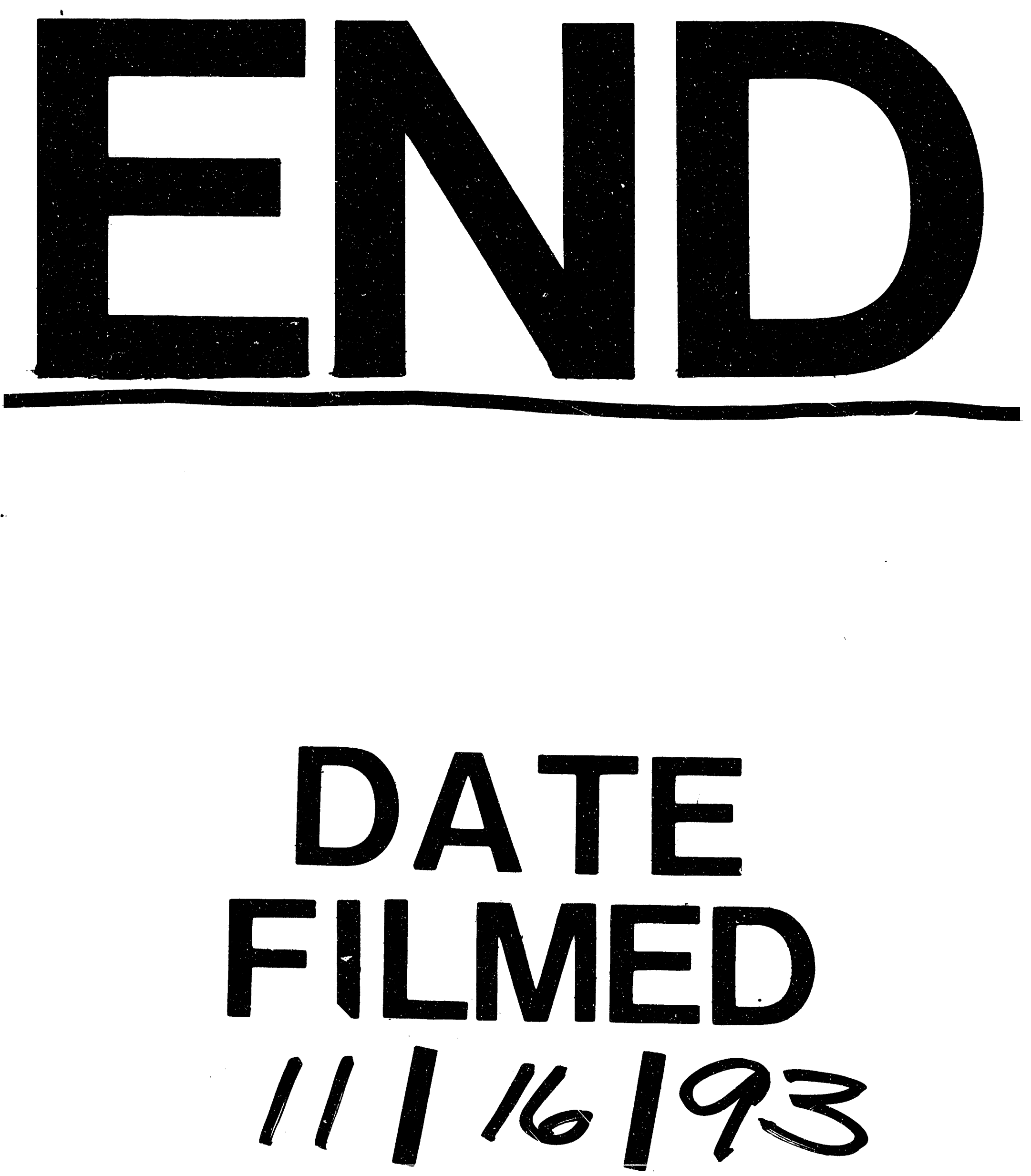

1 
